\title{
Differences in Health and Illness Beliefs in Zimbabwean Men and Women with Diabetes
}

\author{
Esther Mufunda ${ }^{1,2}$, Björn Albin ${ }^{1}$ and Katarina Hjelm ${ }^{*}, 1$ \\ ${ }^{1}$ School of Health and Caring Sciences, Linnaeus University, Växjö, Sweden \\ ${ }^{2}$ Department of Health Sciences, Zimbabwe Open University, Harare, Zimbabwe
}

\begin{abstract}
This study explored beliefs about health and illness that might affect self-care and health-seeking behaviours in Zimbabwean men and women with diabetes. Gender differences were indicated in a previous study but their extent has not been studied. The present study used a qualitative descriptive design with semi-structured interviews to gain a deeper understanding of the phenomena. The sample consisted of 21 participants, 11 females aged 19-61 years (Median 44 years) and 10 males aged 22-65 years (Median 52 years). Qualitative content analysis was used. Health was described as freedom from diseases and enjoying well-being. Both males and females displayed limited knowledge about diabetes and dissimilarities in health-seeking behaviours. Women, in contrast to men, were more active in self-care and used various measures besides drugs as they related to a higher extent the cause of diabetes to supernatural factors like gods and witches. They sought information from self-help groups and help from outside the professional health sector like healers in the folk sector. Prolonged economic disruption also had negative effects towards maintenance of healthy life-styles as both men and women struggled to get money for food and drugs. Thus, the study highlighted that knowledge about diabetes and its management are important for self-care. There is therefore need to develop acceptable and affordable gender- sensitive diabetes care programmes that enhance patient participation, empowerment and promotion of health.
\end{abstract}

Keywords: Diabetes mellitus, gender, health/illness beliefs, health-seeking behaviour, self-care, Zimbabwe.

\section{INTRODUCTION}

Diabetes mellitus is emerging as an epidemic of the $21 \mathrm{st}$ century [1]. It is a significant public health concern because of the demands it places on health care services and individuals $[2,3]$. The pandemic mainly affects developing countries, particularly in Africa [3,4] and the predicted number of affected people will double to 438 million in 2030 [1]. Diabetes and related non-communicable chronic diseases therefore need greater attention as they are associated with high mortality rates and disability in Africa [4, 5].

Most surveys in developing countries indicate that the increase in diabetes is secondary to rapid urbanisation, industrialisation and fast-changing diets marginalising traditional ones in favour of Western diets, worsened by more inactive and sedentary lifestyles $[4,6,7]$. Other risk factors for development of diabetes are increasing age, family history of diabetes with a genetic predisposition, ethnic origin and migration with increased risk for Asian-Indians, adiposity, and immunological factors [3]. Chaufan [8] challenges the "geneslifestyle" framework and argues that the diabetes epidemic is produced not by affluence, but by poverty whose roots lie in inequities in social power. In Zimbabwe, diabetes has been reported to be among the top five chronic conditions seen in outpatient clinics. The latest prevalence reported is $10 \%$ for persons aged above 25 years [9].

\footnotetext{
*Address correspondence to this author at the School of Health and Caring Sciences, Linnaeus University, S- 35195 Växjö, Sweden; Tel: +46 47070 83 05; Fax: +46 470363 10; E-mail: katarina.hjelm@lnu.se
}

A previous study of beliefs about health and illness in Zimbabweans with diabetes [7] indicated gender differences and limited knowledge about diabetes affecting self-care and health-seeking behaviours. Apart from a Ugandan study [10], no study has been found comparing gender differences in beliefs about health and illness in persons with diabetes in Africa. The study [10] showed that women were more aware of risks and seemed to readily undertake precautionary measures while men focused more on technical measures.

Previous investigations have studied men and women separately and found dissimilarities in life modes and thus, risk perceptions $[11,12]$ and health-related behaviour $[13$, 14]. Women were more caring and nurturing and had higher risk awareness than men who were more ego-oriented and willing to take risks. Thus, women perceived diabetes mellitus as intrusive and feared its complications why their daily lives became stressful, watchful and restricted [13]. Men on the other hand saw diabetes as part of their life, tried to limit its restrictions and thus, described a positive impact of the disease on their life-style and believed the complications meant taking better care of themselves [14]. Comparisons of men of different origin, Arabs, exYugoslavians and Swedes, showed that of importance for health were to be gainfully employed, economically independent and able to retain sexual function [15]. Swedes focused on inheritance, life-style and proper management of diabetes while non-Swedes discussed influence of supernatural factors and emotional stress associated with being an immigrant negatively affecting health and thus, causing diabetes. Women of the same origin described health as freedom from disease [16]. Swedes had active self-care behaviour in contrast to a passive attitude in ex- 
Yugoslavians and an information-seeking behaviour in Arabs. Limited knowledge of diabetes mellitus and less perceived seriousness of the disease were indicated in foreign compared to Swedish-born persons, irrespective of gender $[15,16]$.

Most studies done seem to attest how health belief systems shaped by cultural, economic and religious factors affect the experience of health and illness decisions about treatment and satisfaction provided [3, 17]. In developed countries, it has been reported that people find empirical explanations for their illnesses, e.g. diseases, environmental factors or stress, while in developing countries cultural factors tend to influence the perception of illness [18]. The Lay Theory Model of Illness Causation [19] has assumed that westerners focus on causes related to the individual and nature, while non-westerners often tend to discuss the influence of social and supernatural factors.

Zimbabwe, like many other developing countries, is facing the "triple disease burden" with diabetes contributing significantly to the non-communicable disease burden [9]. The economic cost, complications and social consequences of diabetes are also enormous, particularly for the poor. Hence, it is important to understand gender-based beliefs about health and illness in order to promote self-care in persons with diabetes.

\section{MATERIALS AND METHODOLOGY}

\section{The Study}

The aim of the study was to explore beliefs about health and illness that might affect self-care practices and healthseeking behaviour in Zimbabwean men and women who have diabetes mellitus.

\section{Health-Care Delivery System and Diabetes Care in Zimbabwe}

The Zimbabwean Health care delivery system has four levels: the primary, secondary, tertiary and quaternary levels (Table 1). Non-complicated diabetic patients can be managed at both the secondary and tertiary levels, while complicated cases are referred to the quaternary level (central hospital-based diabetes clinics) for further investigations, management of diabetes-related complications and continued diabetes education. Diabetic patients from municipal clinics and doctors' private surgeries at the primary level in the urban areas are also referred to the same clinics. Subsequent follow-ups are done monthly until glycaemic controls are achieved, and then the patients are referred back to the lower levels for continued care [20]. The studied diabetes clinic is under the Department of Internal Medicine at a central hospital and run by a physician specialised in internal medicine, a group of general physicians and non-diabetes specialist nurses. When visiting the clinic blood and urine tests are taken as a preparation for waiting to be seen by the physician. While waiting for the results some health education is sometimes given by the nurses at the clinic but due to work overload this is not regularly organised. Patients are not self-monitoring blood glucose due to lack of equipment or financial resources.

Most health care services are provided by the government $(65 \%)$ complemented by not-for-profit missionary/ church hospitals and private-for-profit institutions [20]. Currently, there is no National Health Insurance system in Zimbabwe. Public health care services are free for pensioners and the under-fives, while others either pay in cash or use private medical aid schemes.

Traditional healers and herbalists are also an integral part of the health care system, represented by the Zimbabwe National Traditional Healers Association [20].

Essential drugs and supplies have been greatly diminished, with stock availability reduced to $22-36 \%$ from 2008. In most cases, drugs to control diabetes were unavailable in most public hospitals and private pharmacies due to the economic crisis and hyperinflation from 2006 to 2009 [9]. Hence some patients either defaulted or bought drugs from nearby countries and from illegal traders on the city streets, while others consulted traditional healers, herbalists etc. for treatment.

Lack of drugs for treatment of diabetes increase the risk for complications and by that also morbidity and mortality [1]. The economic circumstances and reduced quality of care at most health facilities [9] might have forced some diabetic patients to engage in negative illness actions such as healer shopping (going to different care-givers) as they could not afford the high cost of drugs.

\section{Design}

A qualitative descriptive study design was used. Data were collected through semi-structured interviews in order to give the respondents freedom to present their own subjective beliefs and to reach a deeper understanding of the topic being studied [21].

\section{Participants}

A purposeful sampling procedure was used. Persons diagnosed with diabetes mellitus visiting the diabetes clinic were offered, by a nurse (the principal investigator), the opportunity to participate. The inclusion criteria were: diagnosis with diabetes for one year or more, aged $\geq 18$ years, no known psychiatric disorders and able to speak either English or Shona. The respondents were managed in an outpatient diabetes clinic at a central hospital in an urban area also managing persons referred from rural areas.

The sample included 21 participants, 11 females and 10 males, aged 44 (range 19-61) vs 52 years (range 22-65) in median (Table 2).

Most males were on oral agents while insulin treatment was more common amongst females. The majority of the participants were married. Females had a lower educational background than males and most were unemployed while most males were gainfully employed. (Table 2). The same pattern of socioeconomic circumstances was found in a previous report from Zimbabwe [20].

\section{Data Collection}

Each interview started with standardised questions on socio-demographic and medical variables. A thematic interview guide with open-ended questions including common health problems related to diabetes was then used in order to give respondents freedom to express their own 
Table 1. The Zimbabwean Health-Care Referral System and Diabetes Care

\begin{tabular}{|c|c|c|}
\hline Level & Type of Institution & Responsibilities \\
\hline Primary level & Rural clinic & $\begin{array}{l}\text { Manned by nurses and nurse aides. } \\
\text { Initial assessment of diabetic patients } \\
\text { No treatment } \\
\text { Cases are referred to secondary level } \\
\text { No facilities for inpatients. }\end{array}$ \\
\hline Secondary level & District hospital & $\begin{array}{l}\text { Treatment, monitoring, education of referred uncomplicated diabetic cases. } \\
\text { One or two doctors (mostly general practitioners) } \\
\text { Admission of patients. } \\
\text { Complicated cases are referred to level } 3\end{array}$ \\
\hline Tertiary level & Provincial hospital & $\begin{array}{l}\text { Continued management (treatment, monitoring, and education) of diabetics in diabetes } \\
\text { clinics } \\
\text { Limited specialized doctors, general practitioners and nurses } \\
\text { More complicated cases are referred to level } 4\end{array}$ \\
\hline Quaternary level & $\begin{array}{l}\text { Central hospitals and private-for- } \\
\text { profit hospitals }\end{array}$ & $\begin{array}{l}\text { More specialist physicians in internal medicine, general practitioners and general nurses. } \\
\text { Diabetes clinics for management of patients with diabetes- related complications. } \\
\text { Patients are referred back either to level } 2 \text { or } 3 \text { when stable. }\end{array}$ \\
\hline
\end{tabular}

Table 2. Characteristics of the Study Population

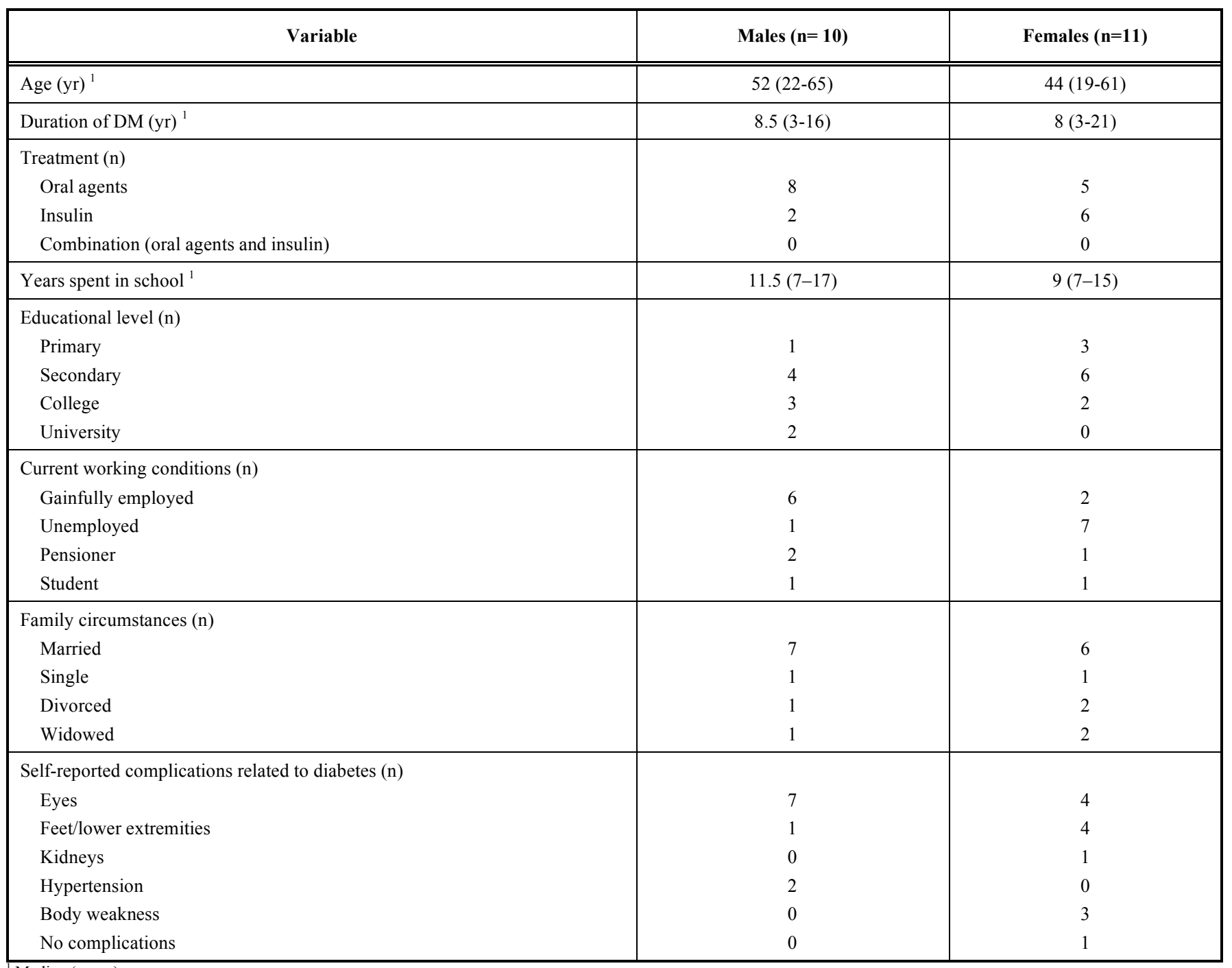


views and obtain a broad range of information in an area that is scarcely studied $[21,22]$. The aim was to describe and explore individual beliefs about health and illness and the influence on self-care and health-seeking behaviour. Themes investigated were: content of health; factors of importance for health, explanations and perceived consequences of diabetes, activities to restore health and care-seeking behaviours. The interview guide was developed based on previous investigations in Sweden $[16,23]$ and in Uganda [10] and peer-reviewed by general practitioners and nurses working in diabetes care. It was translated from English to Shona by the first author and a senior nurse in diabetes care and adapted to the Zimbabwean situation. A pilot-test was made with six persons (not included in the study), and further, minor changes were made to wording and meaning.

Interviews were carried out by a bilingual nurse (first author), who was not involved in the management of the participants. Eighteen interviews were conducted in Shona (according to the participants' choices), and three in English, both of which are two of the three official languages in Zimbabwe [20]. The interviews were held in a secluded room outside the clinic and lasted about 1.5 hours. They were tape-recorded and transcribed verbatim. Transcripts in Shona were then translated into English.

\section{Ethical Considerations}

The study was approved by the hospital Ethics Committee. It was done in accordance with the Helsinki Declaration [24] and with written informed consent from the participants.

\section{Data Analysis}

Qualitative content analysis was used in order to discover and describe the variations in beliefs about health and illness [25]. Collection and analysis of data proceeded concurrently until no new information was added in the analysis. The tapes were listened to after the interviews and notes on themes and contradictions were taken as they emerged from comparisons of the respondents' statements.

The transcripts were read thoroughly several times to achieve a sense of the whole. The texts were broken into smaller textual units where after, each meaning unit was coded and grouped together. Finally, the codes were compared for differences and similarities and sorted into subcategories and main categories (example see Table 3). The focus on the analyses was to be as open to as much variation as possible, and regularities, patterns and contradictions were searched for as the main analytical categories. The Lay Model of Illness Causation [19] and the model for health-care seeking behaviour by [26] were used as previously described [7]. Illness can be perceived as caused by factors related to the individual, natural, social and supernatural worlds [19] and health care sought from the popular (family members), folk (traditional healers, herbalists) and the professional sectors [26]. In order to increase the trustworthiness of the results, data analysis was done independently by two researchers (first and last authors) [25] and comparisons showed a high degree of agreement. Content of categories was also checked by a third researcher (second author), to confirm their relevance [25].

\section{RESULTS}

\section{Beliefs About Health}

Health was described in terms of individual factors, 'freedom from diseases' and 'feeling of well-being'. In order to feel well and experience good health, males (M) focused on compliance with diet, drugs and exercises while females (F) emphasised the importance of diet, drugs and personal and environmental hygiene.

... eat good food; exercise every morning and get treatment on time (M3).

... body-building foods, maintain body and environmental hygiene, follow doctors' instructions about drugs (F1).

All participants acknowledged tangible instrumental support from family members. Provision of money (social factors) for food and drugs was necessary to most participants. Males focused on food provision and preparation and psychological support, in contrast to females who spoke of acceptance and understanding a sick person.

... my children should provide money for medications and transport to go for reviews. Wife to ensure I'm well fed and keep my clothes clean (M3).

... help me to live positively... help with different things ... provision with money for drugs and food (M10).

... accept my condition ... assist when I become sick (F11).

Females considered health professionals to be important for improved health as they assisted with information about diabetes and its management, while men mostly talked about assistance in health maintenance by monitoring of the disease, picking up potential problems and regulation of drugs. In both groups, some mentioned the need for emotional support of diabetics.

... give information ... teach me the does and don'ts ... give advice on food and giving of injections (F1).

... give advice on looking after myself, food preparation, taking of drug ... regular blood sugar monitoring (M3).

As factors harmful to health, both males and females cited the strained economic situation, often leading to overworking (social factors):

... present harsh economic situation ... leads to overworking, no time to rest (M4).

All respondents talked about the negative effects on health caused by their economy, which resulted in being unable to buy medications and/or food, or prescribed drugs which were perceived as expensive. Some said they had less frequent check-up visits while others discussed increased stress and associated diseases:

... situation now too hard ... medication is scarce, everything is expensive...have reduced hospital visits (M10). 
... life has become hard ... take only one meal

a day ... food shortage... drugs scarce and very expensive (F5).

Females also added social problems like being 'ill treated' and 'lack of respect' by relatives. One man talked about harmful influence of smoking/excessive drinking, while others mentioned diseases like hypertension. Irrespective of gender, respondents reported the use of bodily symptoms as a way of checking whether health was improved or worsened; "passing lots of urine, feeling of being tired ... headaches' (M10).

Most males and females talked about compliance with drugs and recommended diet as the main measures to achieve good glycaemic control (individual/nature factors). A few females talked about regular monitoring of blood sugar levels in contrast to only one man. Avoidance of diabetes-related complications was the main reason for achieving good glycaemic control.

... attend monthly check-ups at the doctors' rooms (M16).

... avoid too refined foods, take plenty of vegetables, white meat ... stick to correct drugs (F6).

Measures to improve health when diagnosed with diabetes were mainly prayers (supernatural factors), different household remedies, e.g. Panadol, Aspirin, and herbal teas (natural factors).

... prayers work ... herbal teas (e.g. zumbani), are good for colds, flu and stress (M19).

... Panadol for headaches and bodily pains (M7).

With reference to traditional ceremonies, some participants claimed they never used them while others claimed they 'didn't believe in' them being important for health. Some were 'prohibited by their churches'.

Most females reported contact with self-help groups like the Diabetes Association where they got 'information about diabetes from experts'. Others had 'heard about it but not joined' while some males didn't know about its existence and/or were not interested.

To maintain health and prevent complications, participants reported 'individual' and 'social' factors in terms of compliance with prescribed drugs and check-ups, avoiding and coping with stress. A female talked about adaptation in terms of working hard to earn a living:

... avoid foods that contain too much sugar ... live a life that conforms to diabetes ... attend regular check-ups, test blood sugar levels, take diabetes pills and injections on time (M10).

... find ways to deal with stress (F20).

... follow doctors/nurses' advice about diabetic diet and drugs ... work hard to earn a living (F2).

\section{Beliefs About IIlness}

Most respondents, irrespective of gender, had experienced several symptoms when they fell ill with diabetes, such as passing lots of urine, feeling thirsty, losing weight, sweating and tiredness. With a few exceptions in the female group, none had suspected diabetes. Reactions in both groups included feelings of dying and helplessness. Males suspected sexually transmitted infections, HIV and AIDS, in contrast to a few females who suspected diabetes, malaria and witchcraft. A few participants thought it was natural. Most were seen by doctors/nurses at a clinic (professional sector) after consulting family members (popular sector). Some males consulted their mothers or wives, one female consulted her sister in-law while (popular sector) another visited a witch-doctor (folk sector).

... passing lots of urine, feeling thirsty, drinking lots of water ... got worried ... thought it was an STI ... visited a doctor... later referred to a hospital (M4).

... loss of weight, excessive sweating and passing lots of urine at night.....ignored it initially ... thought it was natural ... later taken to the doctor (M10).

... excessive weight loss, drinking too much water ... thought I had been bewitched. Firstly, I was taken to a ' $n$ 'anga' then to the doctor who later referred me to the hospital (F5).

... feeling tired, weight loss, passing lots of urine, dry mouth ... got confused ... feeling of dying ... Sought help from sister in-law ... was later taken to a doctor (F9).

Different causes of diabetes were stated, e.g. excessive starch intake, pancreatic problems, and antihypertensive drugs (Table 3). Males focused on 'too much sugar intake' through beer/alcohol, while females mainly discussed 'heredity' (individual factor), two claimed witchcraft (supernatural factor), and others were 'not sure'. In relation to discussion of a list of potential causes of diabetes, most talked about heredity, obesity, inactivity, incorrect food, pancreatic diseases (individual factors), drugs such as diuretics (natural factors) and stress (social factor). Supernatural thoughts, e.g. punishment by God and witchcraft, were more often mentioned by females than by males.

Generally, participants knew about what happens in the body when having diabetes and about insulin function. More females than males knew the functions of the pancreas, although knowledge was limited. Females related the pancreas to insulin production, while males either related it to digestion of sugars or were not sure.

Most participants did not use any other name for diabetes besides 'sugar disease; 'diabetes', while a few referred to it as a disease of the evil spirits (chivanhu, chirwere chokumusha kwangu), animal (mhuka) and cancer (nhuta). 
Table 3. Factors that Might Cause Diabetes Mellitus

\begin{tabular}{|c|c|c|c|c|c|}
\hline \multirow{2}{*}{$\begin{array}{l}\text { Main Analytical Category } \\
\text { Factors related to the individual }\end{array}$} & \multirow{2}{*}{$\begin{array}{l}\text { Subcategory with Quotations } \\
\text { Heredity: } \\
\text { ' inheritance...my father suffers from DM' } \\
\text { 'I think heredity.... a number of people from my mother's side have DM' }\end{array}$} & \multicolumn{2}{|c|}{$\begin{array}{l}\text { Statements } \\
\text { by Males (n) }\end{array}$} & \multicolumn{2}{|c|}{$\begin{array}{c}\text { Statements } \\
\text { by Females (n) }\end{array}$} \\
\hline & & 1 & $9^{b}$ & 5 & $7^{b}$ \\
\hline & $\begin{array}{l}\text { Wrong dietary habits: } \\
\text { '...excessive alcohol consumption (kachasu) ... too much sugar in my tea' } \\
\text { '..type of food .... taking sadza, sadza all the time ... too much starch' }\end{array}$ & 2 & $6^{\mathrm{b}}$ & 1 & $5^{b}$ \\
\hline & $\begin{array}{l}\text { Inactivity: } \\
\text { ‘... maybe old age ... no longer active' }\end{array}$ & 1 & $9^{b}$ & & $6^{\mathrm{b}}$ \\
\hline & Obesity $^{\mathrm{b}}$ & & $9^{b}$ & & $8^{b}$ \\
\hline & Stress $^{\mathrm{b}}$ & & $5^{b}$ & & $8^{b}$ \\
\hline & Infection & & $6^{\mathrm{b}}$ & & $5^{b}$ \\
\hline & $\begin{array}{l}\text { Drugs: } \\
\text { '... maybe antihypertensive drugs' } \\
\text { '... hydrochlorothiazide that I was taking for my blood pressure' }\end{array}$ & 2 & $4^{b}$ & 1 & $7^{b}$ \\
\hline & Pregnancy $^{\mathrm{b}}$ & & $2^{b}$ & & $6^{\mathrm{b}}$ \\
\hline & $\begin{array}{l}\text { Diseases of the pancreas: } \\
\text { '...problems with my pancreas' }\end{array}$ & 1 & $6^{\mathrm{b}}$ & 1 & $8^{b}$ \\
\hline \multirow[t]{2}{*}{ Factors related to the social sphere } & Disturbances in social relations ${ }^{\mathrm{b}}$ & & $2^{b}$ & & $1^{\mathrm{b}}$ \\
\hline & The influence of evil people ${ }^{b}$ & & $1^{\mathrm{b}}$ & & $1^{\mathrm{b}}$ \\
\hline Factors related to the nature & Imbalance between warmth and cold ${ }^{\mathrm{b}}$ & & $1^{\mathrm{b}}$ & & $1^{\mathrm{b}}$ \\
\hline \multirow[t]{4}{*}{ Factors related to the supernatural sphere } & Supernatural or religious causes such as evil spirits ${ }^{b}$ & & & & $3^{b}$ \\
\hline & Supernatural or religious causes such as punishment from God or the gods ${ }^{b}$ & & $1^{\mathrm{b}}$ & & $3^{b}$ \\
\hline & $\begin{array}{l}\text { Supernatural or religious causes such as the influence of witches: } \\
\text { '... rather difficult ... thought I had been bewitched' } \\
\text { '... witches can do anything' }\end{array}$ & 1 & $2^{b}$ & 2 & $2^{b}$ \\
\hline & Fate $^{\mathrm{b}}$ & & $3^{b}$ & & $4^{\mathrm{b}}$ \\
\hline
\end{tabular}

${ }^{a}$ Analytical categories, emerging from open ended interview questions, according to the lay model of illness causation by Helman (2007).

${ }^{b}$ Explanations of causes of diabetes mellitus evolved in discussions of a list of potential causes of diabetes mellitus.

The majority of the participants perceived diabetes to be lifelong while some stated 'they didn't know' how long it would last. Most males were treated with oral agents while more females were on insulin. Participants saw provision of diabetes drugs as of paramount importance in the regulation of blood sugar levels.

Both females and males reported diabetes-related physical problems, e.g. backache and reduced/misty vision, however, more frequent in females. A few males talked about hypertension, coma (individual factors) and financial constraints (social factors), while some females discussed inability to perform daily activities and poor support from family members.

I developed high BP, backache and muscle pains ... inability to work for my family (M19).

... passing too much urine, weight gain, reduced vision ... inability to carry out daily chores at home (F17).
... my family is not supporting me and my children (F2).

Most participants expressed fears of diabetes. Males focused on death and getting into coma, while some did not express any fears. All except one female feared visual, kidney, and heart complications while others feared pregnancy-related death and infertility.

Iam afraid of dying (M3).

... diabetes coma (M15).

... kidney damage, coma, painful cramps, misted vision (F21).

I fear infertility and dying from pregnancyrelated complications (F5).

\section{Self-Care and Care-Seeking Pattern}

The majority of the participants except one female reported being informed about regular reviews of disease progress: 
Monthly reviews to check on progress (M15).

Never received any advice (F5).

All participants except two men reported being given advice concerning the importance of monitoring blood glucose using bodily symptoms, conforming to correct diet and avoiding sudden changes of blood sugar levels so as to minimise complications:

I monitor at home ... using bodily symptoms like tiredness, loss of appetite, funny feelings (M3).

When discussing dietary recommendations, all participants, except a few, cited the importance of reducing carbohydrates, increased intake of green vegetables, fruit and regular small meals and snacks. Two females got advice from a dietician. All females had been informed of the importance of regular exercise, but only a few males. Irrespective of gender, all participants had been advised about drug compliance: 'I should take daily drugs on time ... avoid taking unprescribed drugs' (M7).

All participants claimed they followed the advice and one female participant stated: 'It helps me to maintain good health' (F8).

Common diabetes-related health problems, such as hyperglycaemia, repeated episodes of hypoglycaemia, gastrointestinal infection, common colds, pharyngitis, urinary infection, problems with the feet, spasm in the calf and hypertension, were more frequently reported in females than males. They also indicated difficulties in identifying the causes of the problems and stated they were unsure, while males often included an association with diabetes. Most participants had used self-care measures related to the individual sphere (food intake, rest, expectancy), often combined with nature (medications or herbs) and/or the supernatural sphere (prayers and/or holy water) to retain their health. Women exemplified a greater variation in selfcare measures used and mentioned to a higher extent the use of herbs and supernatural measures (prayers and holy water) in comparison to males. When necessary, help was sought from the professional sector (doctors /or nurses) either at the local clinics or at hospitals.

When discussing the occurrence of wounds on the feet, a few had experienced wounds from minor injuries. Help had been sought from the professional sector at clinics/hospitals after self-care cleaning with salt and water.

I was cut by a sharp object ... cleaned with salt and water at home (F5).

I got hurt while cutting firewood ... cleaned the wound with salty water, bandaged it then sought treatment at the clinic (M19).

\section{DISCUSSION}

This study is unique since it is the only one exploring beliefs about health and illness among Zimbabwean men and women with diabetes. Only one similar study has been found from Africa, performed in Uganda [10].

The main findings showed that, irrespective of gender, health was described in a similar way as experiencing freedom from disease and enjoying feeling of well-being.
The strained economic situation was important for health and restricted the possibility to comply with advice about management of diabetes. Nobody described health in accordance with the definition stated by WHO (1946) as “... a state of complete physical, mental and social well-being and not merely the absence of disease or infirmity". However, there were gender dissimilarities in health-related behaviour and explanations of diabetes. Females, in contrast to males, were more active in self-care by using various measures: besides drugs and diet, also herbs, prayers, visiting witch doctors etc. They related, to a higher extent, the causes of diabetes to supernatural factors (e.g. punishment from God, witchcraft). They also searched for information from self-help groups and help outside the professional health sector. These findings might indicate higher risk awareness and a more active health-seeking behaviour in females than males, as previously demonstrated in the Ugandan study of persons with diabetes [10]. In previous Australian studies of diabetic women and men respectively [13, 14], women were found to perceive diabetes as more serious and thus feared the risk of complications, in contrast to men. This is further supported by the fact that males in the present study considered health care professionals as important for health monitoring while females considered them as source of information about diabetes management and self-care advice. Dissimilarities have been demonstrated in life modes and thus, in risk perceptions between men and women in general $[11,12]$.

Possible causes of diabetes were explained in different ways by males and females. Social and supernatural factors were more marked in the female respondents and they had a more fatalistic view, as they discussed factors that were beyond a person's own control [19], e.g. punishment from God, witchcraft, fate etc., similar to the Ugandans [10] and North Africans living in France [27]. This mixture could be related to limited knowledge about diabetes. Males displayed restricted knowledge about diabetes, as demonstrated in the discussions about diabetes and the body functions in relation to it. As assumed among non-westerners, beliefs about health and illness in general were mainly related to social and supernatural factors [19] as well as individual factors. Help was sought to a limited extent from both the folk and the professional sectors [26]. As previously concluded [10], it is important to explore individual beliefs and consider dissimilarities related to gender and living conditions.

Findings from this study showed that prolonged disruption of economic circumstances had negative effects on both females and males, and not only males as reported in the Ugandan study [10]; this was related to inability to buy food and drugs, which demonstrated a conflict between willingness and ability to comply. Such negative disruptions in the economic situation could also engender fears of disruption of body-self, resulting in possible negative illness actions, such as healer shopping and dual use and, eventually, illness inaction [28]. These findings are in agreement with previous discussions that diabetes should be taken as a product of both economic and social poverty [8], as social or economic circumstances may impose insurmountable constraints on healthy lifestyles. Therefore, it might seem pointless to call upon the individuals to adopt lifestyle modification as a major public health strategy if the lifestyles are beyond their reach. However, it is necessary to 
consider giving advice within the socio-economic frameworks that exist.

In this study, most of the females were unemployed and seemed to be affected more than males as they needed money to purchase diabetic drugs from private pharmacies since these were not readily available at most public hospitals because of the economic crisis in Zimbabwe [9]. This might explain why more females than males reported the use of herbs and supernatural measures (prayers, holy water) to control diabetes-related problems.

In all narratives, females and males reported compliance with drugs, diet management and regular monitoring (individual/social factors) to be central in controlling diabetes, although a few males included regular exercise (individual factor) compared to only one female. Almost equal numbers of females and males reported taking insulin, a regime that carries a risk of hypoglycaemia and coma. Therefore, blood sugar monitoring was imperative although none of the participants had the relevant equipment, but reported the use of a variety of bodily symptoms to detect changes in glycaemic control, similar to findings from Uganda [10]. These findings show that health professionals need to give relevant health education about diabetes and its complications to enable the participants to detect changes in their blood sugar levels.

Females more than males claimed to have received limited advice about foot care. Health education/information about foot care should be reinforced to promote health and prevent risks of foot ulcers. However, the lack of relevant diabetes care training, especially for nurses at different levels of the referral system, could mean that this is an area that needs greater attention in the Zimbabwean nurse training curriculum [9].

The study findings also revealed that more females got into contact with the Diabetes Association while males appeared not to be interested or did not know about its existence. The same findings were reported by [29], regarding the impact of gendered beliefs and practice in diabetes care. This finding could also explain the apparent knowledge deficit among the majority of the males on the importance of self-help groups, which could be due to limited exposure. Health promotion education for diabetics therefore needs to be gender-and culture-sensitive [3] in order to address dissimilarities noted in self-care and healthrelated behaviours.

\section{Study Limitations}

Participants in this study were recruited from a central hospital-based diabetes clinic. This might mean that it would be difficult to generalise the study findings to the larger population of persons with diabetes in Zimbabwe, as they are also treated at other levels of the health care system. However, it is assumed that the sample was representative since some patients who ended up at this quaternary level were referred from the other lower levels of the health care system.

Results from qualitative studies are not able to generalise to a wider population [21]. The principle of saturation guided the study why data collection and analysis proceeded simultaneously until no new information emerged [21]. This could however, enable transferability of findings to populations with similar characteristics.

Using both open-ended and closed questions, with probing for detailed knowledge of beliefs, made an in-depth understanding possible and increased trustworthiness of data [21]. In-depth interviews also made it possible to reveal unconscious beliefs, and thus avoided the frequently criticised superficial knowledge collected through structured interviews or questionnaires.

\section{Implications for Nursing Practice}

Since gender, socio-cultural and economic factors are likely to influence health-related behaviours in patients with diabetes; an exploration of gender differences in health beliefs is an important step towards an understanding of preventive practices and future educational needs of people with diabetes. The level of knowledge in the patients was not focused in this study but need to be further investigated and provides a base for how education can be conducted. The apparent limited knowledge shown by both males and females might mean that a preventive approach needs to be adopted in the dissemination of diabetes-related health education, targeting individuals and different community groups in order to make them aware of diabetes and self-care management. Nurses play an important role in this since they contribute the majority of health-care personnel [9], and make first contact with patients in most Zimbabwean healthcare settings as well as in other sub- Saharan countries.

Previous studies have reported that people who believe in a combination of biomedical, cultural and religious aetiology of their disease (a fatalistic belief), may also believe that they have little control over the course of their illness [30]. Thus, it is necessary for health professionals to explore the beliefs of males and females with diabetes and provide education on its multiple causes (including genetic and lifestyle causes) and recognising their cultural and religious beliefs. Furthermore, there is a need to explore alternative locally available traditional foods and herbs in view of the prevailing economic hardships, so that conformity to diabetic dietary requirements is maintained. This might enhance active participation in self-care.

\section{CONCLUSION}

The study showed that Zimbabwean males and females with diabetes have different beliefs about health and illness which affect health-seeking behaviours. Females were more active in self-care and searched for more information in order to adapt to the condition, while males tended to adopt a rather passive attitude.

Although both males and females reported the need for compliance with diabetic drugs and diet, economic hardships and poverty were cited as the major drawbacks in the maintenance of healthy lifestyles. Knowledge of gender beliefs about health and illness in an economically strained country like Zimbabwe would help in the development of appropriate gender-sensitive health promotion programmes and interventions that are affordable, acceptable and achievable. It also means that governments in developing countries need to be more committed in addressing the issue of the emerging problem of diabetes as a "silent killer" 
which is contributing significantly to premature deaths and disabilities among the productive population in Africa $[4,5]$.

\section{ACKNOWLEDGEMENTS}

We are grateful to Senior Tutor Ms Grace Nambozi, Mbarara University of Science and Technology (MUST) Uganda, for helpful criticism and stimulating discussions in designing the study and analysing data.

This work was supported by grants from The Research Committee at the School of Health Sciences and Social Work, University of Växjö, and The Linnaeus-Palme Foundation, Swedish International Development Aid (SIDA), Sweden, enabling joint international collaboration in Sweden and Zimbabwe.

\section{CONFLICT OF INTEREST:}

The authors declare that they have no competing interests.

\section{REFERENCES}

[1] International Diabetes Federation. Diabetes Prevalence. Montreal 2009. [cited 2011 May 10]. Available from: http://www.diabetesa tlas.org/content/what-is-diabetes

[2] Shilubane HN, Potgieter E. Patients and family member's knowledge and views regarding diabetes mellitus and its treatment. Curationis 2007; 30: 58-65

[3] Mbanya JC, Motala AA, Sobngwi E, Assah FK, Enoru ST. Diabetes in sub-Saharan Africa. Lancet 2010; 375: 2254-66.

[4] Gill GV, Mbanya JC, Ramaiya KL, Tesfaye S. A sub-Saharan African perspective of diabetes. Diabetologia 2009; 52: 8-16.

[5] World Health Organization. WHO Overview-Preventing Chronic Diseases: a vital investment 2011. [cited 2011 May 24]. Available from: http://www.who.int/chp/chronic disease report/partl/en/index7.html

[6] Hjelm K, Mufunda E, Nambozi G, Kemp J. Preparing nurses to face the pandemic of diabetes mellitus: a literature review. J Adv Nurs 2003; 41: 424-34.

[7] Hjelm K, Mufunda E. Zimbabwean Diabetics' beliefs about health and illness: an interview study. BMC Int Health Hum Rights 2010; 10: 7 .

[8] Chaufan C. What does justice have to do with it? A bioethical and sociological perspective on the diabetes epidemic. Adv Med Sociol 2008; 9: 269-300

[9] Ministry of Health and Child Welfare. National Health Strategy for Zimbabwe 2009-2013: Equity and Quality in Health: A People's Right. Zimbabwe: MOHCW 2009.

[10] Hjelm K, Nambozi G. Beliefs about health and illness: a comparison between Ugandan men and women living with Diabetes Mellitus. Int Nurs Rev 2008; 55: 434-41.

[11] Jakobsen L. Livsform, kön och risk. En utveckling och tillämpning av realistisk livsformsanalys (Life-Mode, Gender and Risk.
Development and Application of Realistic Life-Mode Analysis) Lund: Arkiv Förlag 1999.

[12] Jakobsen L, Karlsson JCH. Arbete och kärlek. En utveckling av livsformsanalys (Work and Love. A Development of Life-Mode Analysis). Lund: Studentlitteratur 1993.

[13] Koch T, Kralik D, Sonnack D. Women living with type II diabetes: the intrusion of illness. J Clin Nurs 1999; 8: 712-22.

[14] Koch T, Kralik D, Taylor J. Men living with diabetes: minimizing the intrusiveness of the disease. J Clin Nurs 2000; 9: 247-54.

[15] Hjelm K, Bard K, Nyberg P, Apelqvist J. Beliefs about health and illness in men with diabetes mellitus of different origin living in Sweden. J Adv Nurs 2005; 50: 47-59.

[16] Hjelm K, Bard K, Nyberg P, Apelqvist J. Religious and cultural distance in beliefs about health and illness in women with diabetes mellitus of different origin living in Sweden. Int J Nurs Stud 2003; 40: $627-43$.

[17] Chalmers B. Western and African conceptualization of health Psychol Health 1996; 12: 1-10.

[18] Furnham A, Akande D, Baguma P. Beliefs about health and illness in three countries: Britain, South Africa and Uganda. Psychol Health Med 1999; 4(2): 189-201.

[19] Helman C. Culture, Health and Illness. 5th ed. London: Hodder Arnold Publishers 2007.

[20] Ministry of Health and Child Welfare. National Health Strategy for Zimbabwe, 1997-2007: Working for Quality and Equity in Health. Zimbabwe: MOHCW 1997.

[21] Patton MQ. Qualitative Research and Evaluation Methods. London: Sage 2002.

[22] Sandelowski M. Focus on research methods. Whatever happened to qualitative description? Res Nurs Health 2000; 23: 334-40.

[23] Hjelm K, Nyberg P, Apelqvist J. Beliefs about health and illness essential for self-care practice: a comparison of migrant Yugoslavian and Swedish diabetic females. J Adv Nurs 1999; 30: 1147-59.

[24] World Medical Association. Declaration of Helsinki: Ethical Principles for Medical Research Involving Human Subjects 2008. [cited 2011 May 24] Available from: http://www.wma.net/en/30 publications/10policies/b3/

[25] Krippendorff K. Content Analysis. An Introduction to its Methodology. London: Sage 2004.

[26] Kleinman A. Patients and Healers in the Context of Culture. Berkeley, CA: University of California Press 1980.

[27] Dechamp-Le-Roux C, Valensi P, Assad A, Sislian P, Attali JR. Croyances des diabétiques sur l'étiologie de leur maladie. Influence de l'ethnie. (Etiological beliefs in diabetic patients. Influence of ethnic origin). Diabete Metab 1990; 16: 207-12.

[28] De-Graft Aikins A. Living with diabetes in rural and urban Ghana: A critical social psychological examination of illness action and scope for intervention. J Health Psychol 2003; 8: 557-72.

[29] Alberti H, Alberti B. The influence of gender on primary care management of diabetes in Tunisia. Pan Afr Med J 2009; 3: 1-11. [cited 2011 May 10] Available from: http://www.panafricanmed-journal.com/content/article/3/2/full

[30] Hatcher E, Whittemore R. Hispanic adults' beliefs about type 2 diabetes: Clinical implications. J Am Acad Nurse Pract 2007; 19: 536-45. 